\begin{tabular}{|l|l|l||}
\hline \multicolumn{2}{|c|}{ PublisherInfo } \\
\hline \hline PublisherName & $:$ & BioMed Central \\
\hline \hline PublisherLocation & $:$ & London \\
\hline \hline PublisherImprintName & $:$ & BioMed Central \\
\hline \hline
\end{tabular}

\title{
EGF receptor: new trick for an old dog?
}

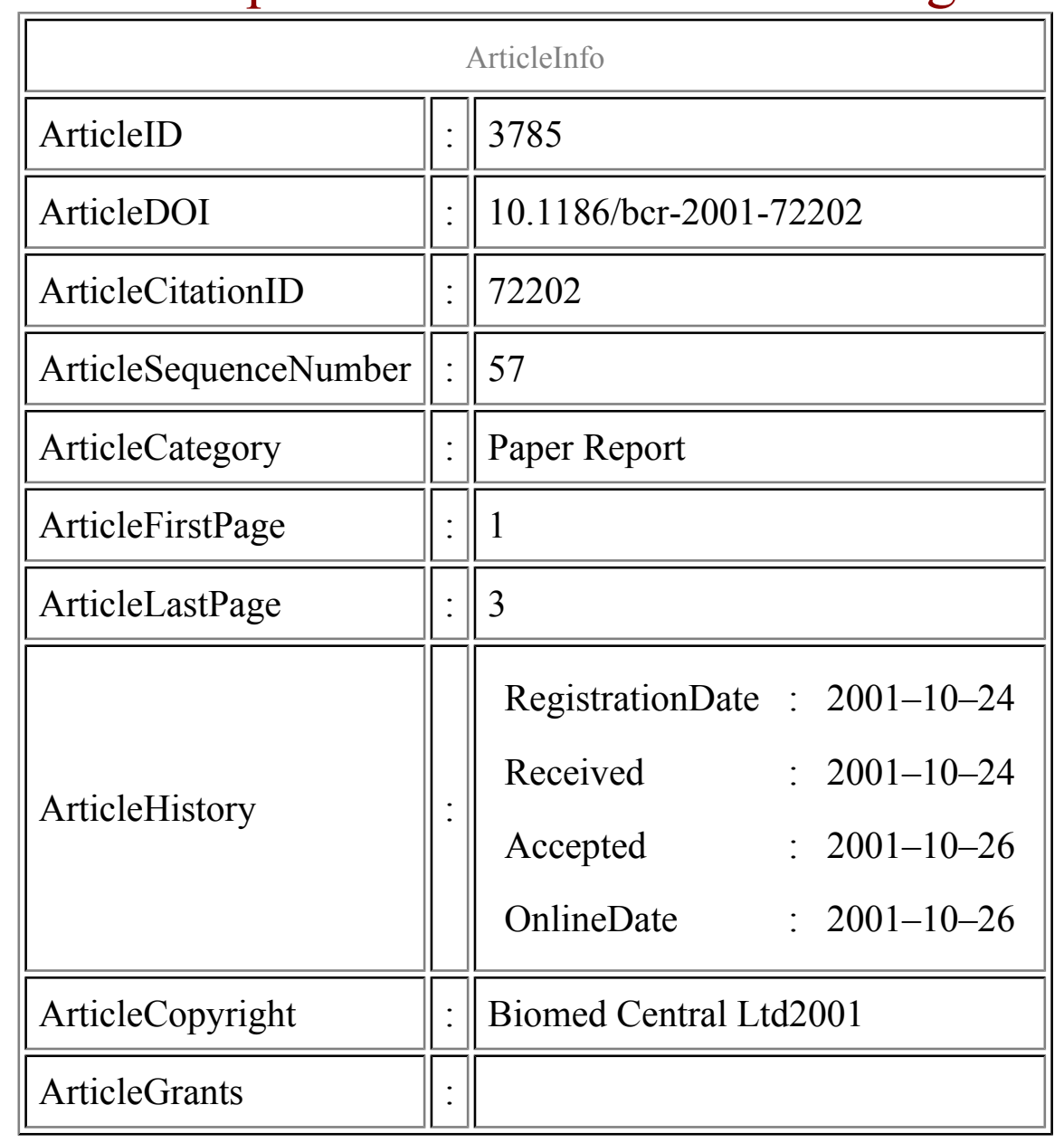




\begin{tabular}{|l|l|l|l|}
\hline ArticleContext & $:$ & 1305833 \\
\hline
\end{tabular}

Douglas Yee, ${ }^{\text {Aff1 }}$

Aff1 University of Minnesota Cancer Center, Minneapolis, MN, USA

\section{Keywords}

EGF receptor, pathogenesis and cell biology, transcriptioin factors

\section{Context}

Breast cancer biology is regulated by members of the epidermal growth factor receptor (EGFR) family. Traditionally, effects of these plasma membrane-associated tyrosine kinase receptors have been attributed to the activation of multiple diverse intracellular signaling pathways. However, nuclear localization of the EGFR has been documented although the function of these nuclear receptors is uncertain. In this study, the authors suggest that nuclear EGFR may function as a transcription factor.

\section{Significant findings}

Nuclear localization of the EGFR was documented. Transport of EGFR to the nucleus appeared to be ligand dependent, although, in EGFR-amplified cell lines, there appeared to be some constitutive nuclear EGFR. A transactivation domain was shown to be present in the $\mathrm{C}$ terminus of EGFR. Complexes of EGFR bound an AT-rich minimal consensus sequence (ATRS). Since the cyclin D1 promoter contains an ATRS, the authors used cyclin D1 promoter reporter constructs to show increased transcription after EGF treatment in MDA-468 breast cancer cells. Importantly, the authors showed that an EGFR complex could directly bind the cyclin D1 promoter. The authors concluded that EGFR can be transported into the nucleus after activation, and function as a transcription factor.

\section{Comments}

It is unquestionable that EGFR and its family members play an important role in the biology of normal and malignant breast epithelial cells. Therapies targeted at the EGFR family members are 
finding their way into the standard treatment of breast cancer. While the signaling pathways initiated by EGFR family members involve activation of numerous intracellular proteins, this paper suggests that EGFR may directly affect DNA transcription with few intermediate molecules. Although the authors do not show how EGFR can be transported into the nucleus or if EGFR directly binds DNA, they provide convincing evidence that and EGFR complex participates directly in the transcription activation of cyclin D1, a key regulator of cell cycle progression. It is not certain how signaling initiated from the cell membrane by EGFR differs from the effects of nuclear EGFR on breast cancer cells, and it will be a difficult task to separate the biology attributable to each pathway. It is also not clear if cells with lower levels of EGFR expression have similar nuclear functions. However, given the emergence of anti-EGFR strategies (monoclonal antibodies and tyrosine kinase inhibitors) as cancer treatments, a complete understanding of EGFR function will be necessary to select patients for anti-EGFR treatments and to determine which type of anti-EGFR strategy should be employed for individual patients.

\section{Methods}

Immunohistochemistry, gene reporter constructs, cyclic amplification and selection of targets, chromatin immunoprecipitation, nuclear fractionation

\section{Additional information}

\section{References}

1. Lin SY, Makino K, Xia W, Matin A, Wen Y, Kwong KY, Bourguignon L, Hung MC: Nuclear localization of EGF receptor and its potential new role as a transcription factor. Nat Cell Biol. 2001, 3: 802-808. 